\title{
Sliding Mode Extremum Seeking Control for Maximum Power Point Tracking in Wind System
}

\author{
Dan Shen, Pardis Khayyer, Afshin Izadian, Senior Member, IEEE \\ Energy Systems and Power Electronics Laboratory \\ Purdue School of Engineering and Technology, Indianapolis 46202, USA
}

aizadian@,iupui.edu

\begin{abstract}
This paper proposes a sliding mode extremum seeking control (SM-ESC) for maximum power point tracking (MPPT) in variable speed wind energy conversion system, which includes the permanent magnet synchronous generator (PMSG), the uncontrolled rectifier, boost converter, battery and the DC constant power load (CPL). The presented MPPT control method integrates the theory of sliding mode control and the extremum seeking control. It refrains from some disadvantages in traditional wind MPPT methods, such as detecting the gradient of output power vs. rotor speed, longer transient response, high frequency noise and larger oscillations of output power. The specific working principle and adaptive step size setting of the MPPT controller are also analyzed based on the SMESC algorithm. Numerical simulation results demonstrate accurate operation and robustness of the MPPT algorithm in each operating condition.
\end{abstract}

\section{INTRODUCTION}

Growing concerns over increase in greenhouse gas emissions, global environmental deteriorations and sustainable development, has increasingly shifted interest of energy experts towards integration of renewable energy sources in the power systems. Compared with other clean energies, wind power have been proved as one acknowledged potential source of energy, due to the characteristics of inexhaustible, high-efficiency and environment-friendly. However, some technical problems are still accompanied with wind integrated utilization, e.g. instability caused by the load variations and intermittency of wind.

In order to meet the load requirements and increase the overall system reliability, many renewable energy systems are utilized in conjunction with energy storage units. [1],[2],[3]. For instance, small-scale standalone wind power system has been established effective in many related and remote areas. Simultaneous intermittency of wind can be compensated by utilization of energy storage devices.

Presented wind energy conversion DC system has shown several advantages with respect to some traditional AC systems. Firstly, with the increasing applications in DC load, this DC system can generate a higher quality power with lower harmonics, because the output power can be completely uninterrupted by controlling switched-mode power converters [4], [5], allowing the final aggregation of standalone energy sources to the main dc grid [6], [7]. Secondly, being equipped with the directly-driven Permanent Magnet Synchronous Generator (PMSG) eliminates the need of gear box coupling the wind turbine to generator in normal variable speed wind systems. There are many problems associated with this mechanical element, such as high-cost maintenance requirement and considerable faults. In addition, PMSGs are getting increasing acceptance because of some preferred characteristics which are reduction of the cost and weight of wind turbine, fast dynamic response, ease of installation and low noise [8]. Thirdly, due to the nonlinear relationship between the rotor speed and the wind turbine output power, it is very important to maximize and maintain the utilization coefficient by applying the maximum power point tracking methods under the variations of wind speed. Generally, there are three traditional types of the wind MPPT techniques: 1) power signal feedback (PSF) control, 2) tip speed ratio (TSR) control, and 3) perturbation and observation (P\&O) control. The control of theses MPPT methods depends on the maximum power characteristics curve resulting from simulation or field tests, requirement of wind information and perturbation of rotor speed respectively, which are limited by the complexity of the sensors and the big oscillations [9]-[13]. Relay Extremum Seeking Control (ESC) has been one commonly MPPT algorithm for both solar and wind systems in recent years. But relay ESC force the wind system to track the maximum power point by increasing or decreasing one suitable control signal depends on the sign of the gradient of output power vs. rotor speed, which can amplify the noise and lead to the instability issues at high frequency. In order to eliminate the gradient sensors in relay ESC method, sliding mode theory in extremum seeking control has been introduced from the references [14] and [15]. Although the similar techniques have been used in both solar MPPT and wind MPPT, there are two main differences between the developed methods and proposed strategy: 1) the controlled objective is not DC-DC converter but AC-DC inverter [16] [17]. 2) the load-side in the proposed wind system is not just a resistor [18] [19] but the dynamic load which includes battery and the DC constant power load, Therefore, applying the SM-ESC in the proposed wind system will be a novel and significant attempt, which can be more general in the practical applications.

This paper is organized as follows. The proposed wind energy generation unit is shown in section II. The MPPT method for wind system by utilizing the sliding mode control theory in extremum seeking control strategy is discussed in section III. Section IV represents some related simulation results. Finally, the conclusions and comments on the performance of proposed control technique are summarized in section $\mathrm{V}$. 


\section{WIND ENERGY GENERATION UNIT}

Figure 1 depicts the proposed topology of wind power system consisting of wind turbine, uncontrolled universal bridge, Permanent Magnet Synchronous Generator (PMSG), DC-DC boost converter interfaces a battery and a DC constant power load which composes a DC motor and a local proportion and integration (PI) power controller. Thus the $\mathrm{AC}$ power is converted to DC power and delivered to the boost converter, which can be regulated by MPPT controllers based on SM-ESC theory. The controller receives the mechanical output power from the wind turbine and operates a maximum-power-point tracking (MPPT) algorithm to send and adjust the pulse width modulation (PWM) signal for the booster circuit regarding the level of power coefficient $\mathrm{C}_{\mathrm{p}}$.

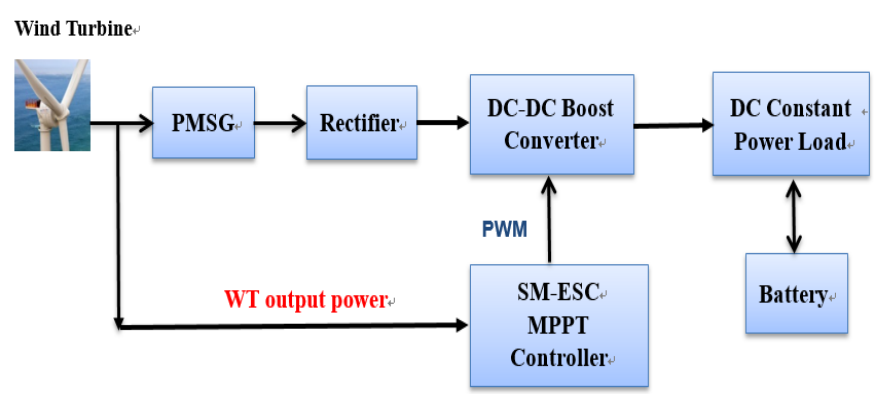

Fig. 1. Proposed wind energy generation system.

\section{SLIDING MOdE EXTREMUM SEEKING CONTROL FOR WIND MPPT}

Wind system can absorb the wind energy and convert them into electric energy through the power electronics devices. A typical wind generation system is composed of wind turbine, generator, universal bridge, and the power converters or inverters. The generator is driven by the torque which comes from the rotation of the wind turbine. Then the universal bridge is used to make the AC power to DC power and supply the source voltage of power converters. The maximum power point can be obtained by tuning the controller and applying the appropriate PWM signal for the converter. Some MPPT control methods have also been proposed for wind generation system to eliminate the probable mismatch between wind power and its ideal maximum power under different climates. In this way, tracking MPP is quite important for wind system not only to enhance the efficiency of system but also to reduce the cost of energy. Hence this section will focus on the wind MPPT controller design based on the sliding mode extremum seeking control approach.

\section{A. Modeling of Wind Power System}

The fundamental formula determines the output power of wind turbine is given by:

$$
\mathrm{P}=\frac{1}{2} p A V^{3} C_{p},
$$

where, $\rho$ is the air density $(\mathrm{kg} / \mathrm{m} 3)$, which is $1.29 \mathrm{~kg} / \mathrm{m} 3$ in this paper. $A$ is swept area of rotor blads, $V$ is wind speed $(\mathrm{m} / \mathrm{sec})$, $\mathrm{C}_{\mathrm{p}}$ is the wind power utilization coefficient, the theoretical maximum value of $\mathrm{C}_{\mathrm{p}}$ is around 0.593 based on the Betz Theory.
The tip speed ratio $\lambda$ and power conversion value $C_{p}$ can be obtained as follows:

$$
\begin{aligned}
& \lambda=\frac{\omega R}{V}=\frac{2 \pi R n}{V}, \\
& C_{p}(\lambda, \beta)=c_{1}\left(\frac{c_{2}}{\lambda_{i}}-c_{3} \beta-c_{4}\right) e^{-\frac{c_{5}}{\lambda_{i}}}+c_{6} \lambda, \\
& \frac{1}{\lambda_{i}}=\frac{1}{\lambda+0.08 \beta}-\frac{0.035}{\beta^{3}+1} .
\end{aligned}
$$

In the above formula, $\omega$ is the wind turbine shaft speed $(\mathrm{rad} / \mathrm{s}), \mathrm{n}$ is the wind turbine rotational speed $(\mathrm{r} / \mathrm{s}), R$ is the radius of the blades ( $R=2.5 \mathrm{~m}$ in this paper), and $C_{1}=0.5176, C_{2}=116$ , $C_{3}=0.4, C_{4}=5, C_{5}=21, C_{6}=0.0068$. In this paper, the wind power system consists of a fixed pitch angle ( 0 degrees) and variable speed wind turbine, a permanent magnet synchronous generator (PMSG), and a diode bridge rectifier is built and applied in Matlab/Simulink. The wind turbine torque and rotor speed are equal to the generator torque and rotor speed due to their direct connection without a gearbox. Figure 2 shows the characteristics of the wind turbine output power vs. rotor speed. The nonlinear curve of $\mathrm{C}_{\mathrm{p}}-\lambda$ is also illustrated in Figure 3, with the optimal tip speed ratio around 8.1 and maximum power coefficient 0.48 [20].

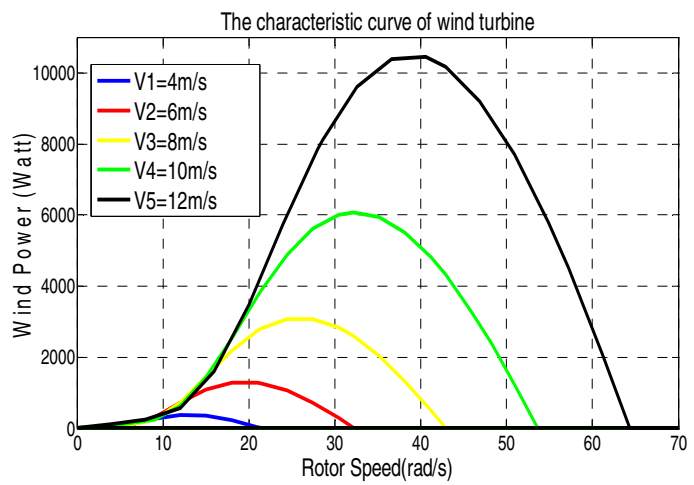

Fig. 2. Wind turbine power vs. rotor speed

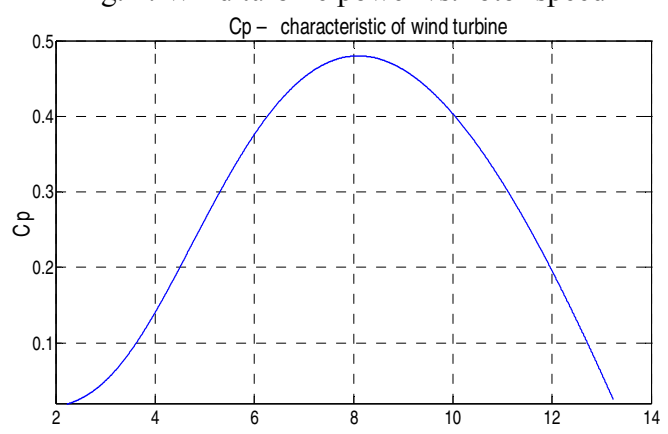

(b)

Fig. 3. $C p-\lambda$ characteristic of wind turbine $(\beta=0)$.

\section{B. Maximum Power Point Tracking Technique}

In order to catch the $\mathrm{C}_{\mathrm{pmax}}$ from the nonlinear curve of $\mathrm{C}_{\mathrm{p}}-\lambda$ and improve the MPPT performance of ESC method, this paper presents the SM-ESC to further enhance the output response of wind power by combining sliding mode and extremum seeking control theories. Although conventional ESC MPPT has already 
been used well in many solar and wind applications [21], the switching function sign (s) usually operates at infinite frequency to reach the ideal condition. Such high switching frequency cannot be accomplished in actual systems and also make the output unstable with creation of high frequency noise (chatter) [22]. Hence, the sliding layer control concept which effectively avoids the operation of continuous switching is proposed. A three states function of sliding layer will replace sign (s) as follows [23]:

$$
\operatorname{sat}(\mathrm{s}, \alpha)=\left\{\begin{array}{cc}
1, \quad s>\alpha \\
\frac{s}{\alpha}, \quad|s| \leq \alpha \\
-1, \quad s<-\alpha
\end{array}=\left\{\begin{array}{c}
\operatorname{sign}(s),|s|>\alpha \\
\frac{s}{\alpha}, \quad|s| \leq \alpha
\end{array}\right.\right.
$$

The switching space can be separated into three regions, namely $s>\alpha,|s| \leq \alpha$, and $s<-\alpha$, where $|s| \leq \alpha$ indicates the sliding layer, $\alpha$ represents the thickness of the sliding layer. The function $\operatorname{sat}(s, \alpha)$ is showing switching surface for a manifold defined by $\{\mathrm{x}: \mathrm{s}(\mathrm{x})=0\}$. As shown in Figure 4, SMESC utilizes the three states switch to replace sign (s) in ESC and can achieve better effect of high frequency oscillation. Figure 5 is the wind MPPT scheme based on SM-ESC [18], [24], in which the variable s represents the sliding surface.

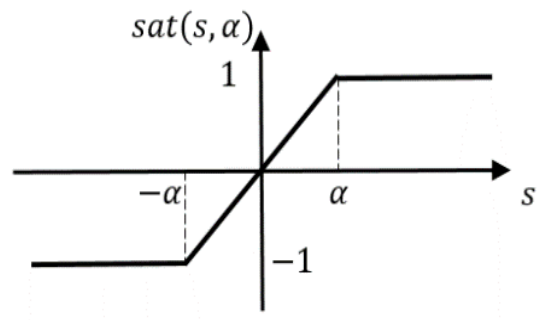

Fig .4. Sliding layer concept.

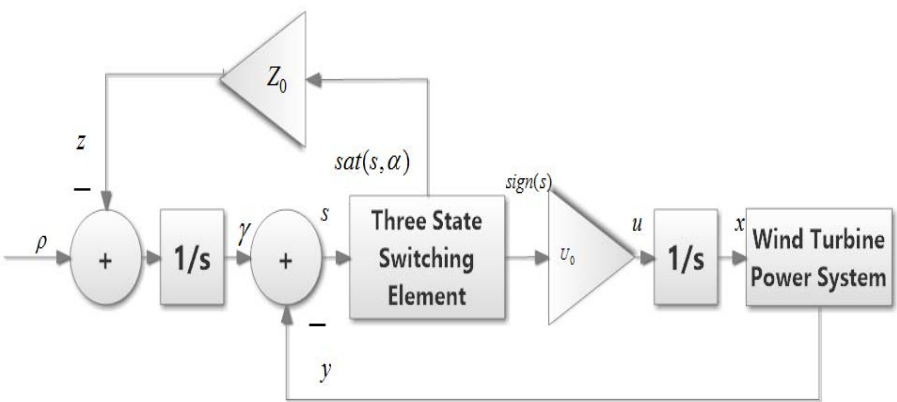

Fig.5. Block diagram of sliding mode ESC algorithm

The specific parameters of the controller in Figure 5 can be expressed as follows:

$$
\begin{aligned}
& \mathrm{s}=\gamma-\mathrm{y} \\
& \mathrm{u}=U_{0} \operatorname{sign}(s) \\
& \frac{\mathrm{d} \gamma}{\mathrm{dt}}=\rho-\mathrm{z} \\
& \mathrm{z}=Z_{0} \operatorname{sat}(\mathrm{s}, \alpha) \\
& \mathrm{d}=\mathrm{G}+\mathrm{u}
\end{aligned}
$$

where $\rho, Z_{0}, U_{0}$ and $G$ are constants; $x$ is the input control signal for the wind energy system; $y$ is the mechanical output power of wind turbine. The variable $d$ is duty cycle of the DC-DC boost converter. This has to satisfy the following relationship $Z_{0} \gg \rho$ and $Z_{0} \gg U_{0}$. For MPPT controller rely on SM-ESC in this system, we choose $\rho=250, Z_{0}=15000, \alpha=0.02$ and $\mathrm{G}=0.7$.

Parameter $\mathrm{U}_{0}$ presents the step size of controller. The adaptive step size based on the wind speed variations is also applied in SM-ESC for tuning control signal. Initially, $\mathrm{U}_{0}$ is $12 \mathrm{e}-$ 5 because it cannot be too large or too small due to the requirements of tracking speed and stability of the system. When the system operating point is approaching to the MPP, which means the absolute value of power variation is smaller than $2 \mathrm{~W}$ and the power coefficient $C_{p}$ is over 0.4795 , so that the step size $\mathrm{U}_{0}$ should changes to $2 \mathrm{e}-5$ by using the Hysteretic Comparator with the sampling time $0.005 \mathrm{sec}$, which can make the elapsed time exceed five time constant of the circuit. Hence, the current and voltage could reach steady-state response around maximum power point. Moreover, we have different step size regarding the wind speed changing. $\mathrm{U}_{0}$ is $5 \mathrm{e}-5$ with positive perturbation and $12 \mathrm{e}-5$ with negative perturbation when wind speed is increasing; $\mathrm{U}_{0}$ is $12 \mathrm{e}-5$ with positive perturbation and $5 \mathrm{e}-5$ with negative perturbation when wind speed is decreasing.

The MPPT tracking profile, wind power coefficient and tuning signal for PWM under the wind speed changing from $7 \mathrm{~m} / \mathrm{s}$ to $8 \mathrm{~m} / \mathrm{s}$ to $9 \mathrm{~m} / \mathrm{s}$ to $10 \mathrm{~m} / \mathrm{s}$ are illustrated in Figure 6 . Figure 7 demonstrates the MPPT tracking profile, the power and coefficient tuning signal for PWM with the variations of wind speed from $10 \mathrm{~m} / \mathrm{s}$ to $9 \mathrm{~m} / \mathrm{s}$ to $8 \mathrm{~m} / \mathrm{s}$ to $7 \mathrm{~m} / \mathrm{s}$. As represented in the figures, the $C_{p}$ value always remains at the maximum level 0.48 .

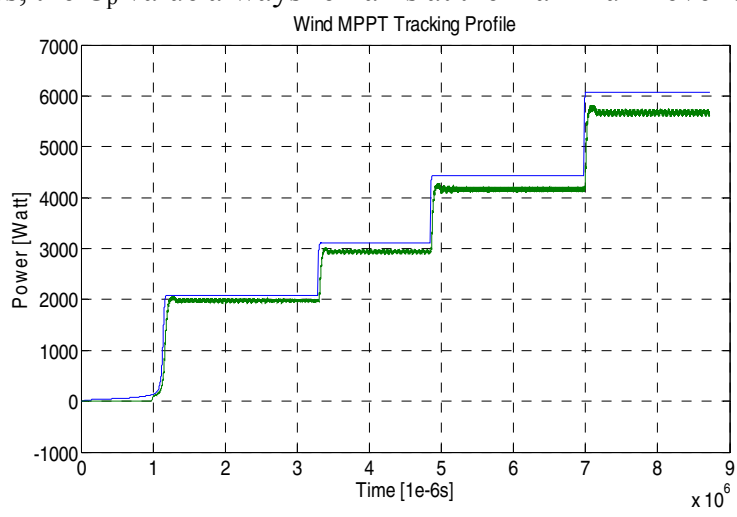

(a) MPPT tracking profile

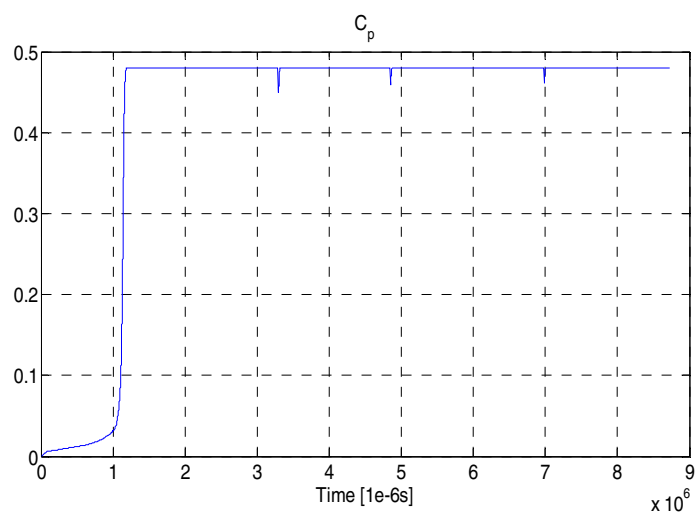

(b) Wind power coefficient 


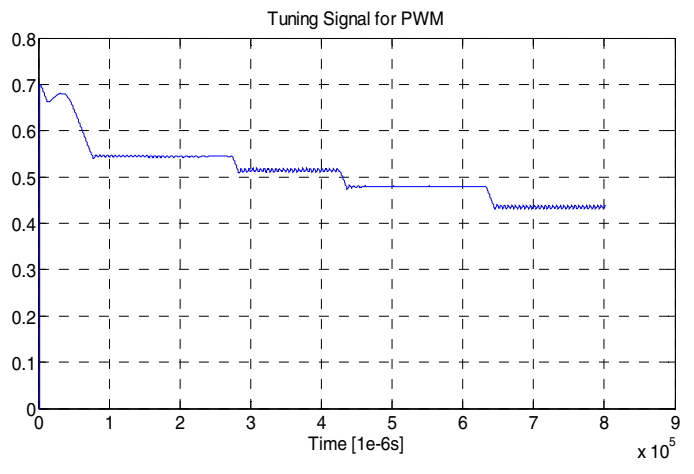

(c) Tuning signal for PWM

Fig. 6. System dynamic response when wind speed changing from $7 \mathrm{~m} / \mathrm{s}$ to $8 \mathrm{~m} / \mathrm{s}$ to $9 \mathrm{~m} / \mathrm{s}$ to $10 \mathrm{~m} / \mathrm{s}$

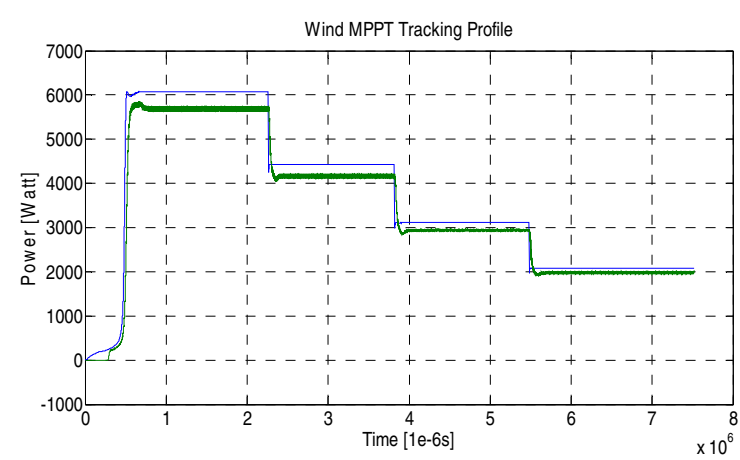

(a) MPPT tracking profile $\mathrm{C}_{\mathrm{p}}$

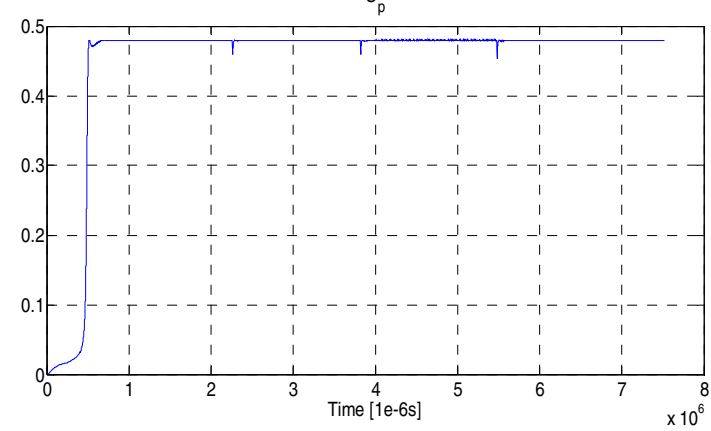

(b) Wind power coefficient

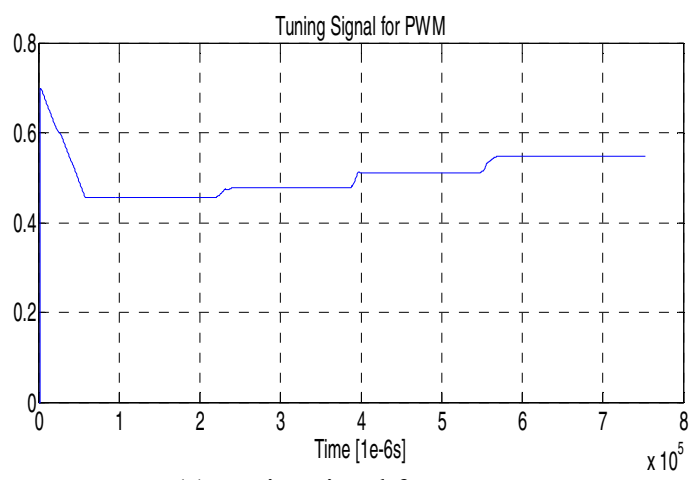

(c) Tuning signal for PWM

Fig. 7. System dynamic response when wind speed changing from $10 \mathrm{~m} / \mathrm{s}$ to $9 \mathrm{~m} / \mathrm{s}$ to $8 \mathrm{~m} / \mathrm{s}$ to $7 \mathrm{~m} / \mathrm{s}$

\section{NUMERICAL SimUlATIONS}

The whole system with SM-ESC MPPT controller is simulated in Matlab/Simulink. The functionality of the proposed system has also been verified in the following figures, the sample time of the simulations has been set to 1e-6s. Regarding the lead-acid battery used in the system, the terminal voltage of battery is $229 \mathrm{~V}$ when SOC is $30 \%$ and the terminal voltage is around $245 \mathrm{~V}$ when the SOC over $95 \%$. Thus the DC bus voltage should show that it can be controlled to a certain extent for charging or discharging the battery. Figure 8 and Figure 9 represent the system responses under a step change of the DC load voltage from $220 \mathrm{~V}$ to $255 \mathrm{~V}$ and $255 \mathrm{~V}$ to $220 \mathrm{~V}$ to show the feasibility of the control system. It can be observed that increasing or decreasing the DC bus voltage in appropriate range will not affect to capture the maximum power of the wind turbine in the proposed control strategy.
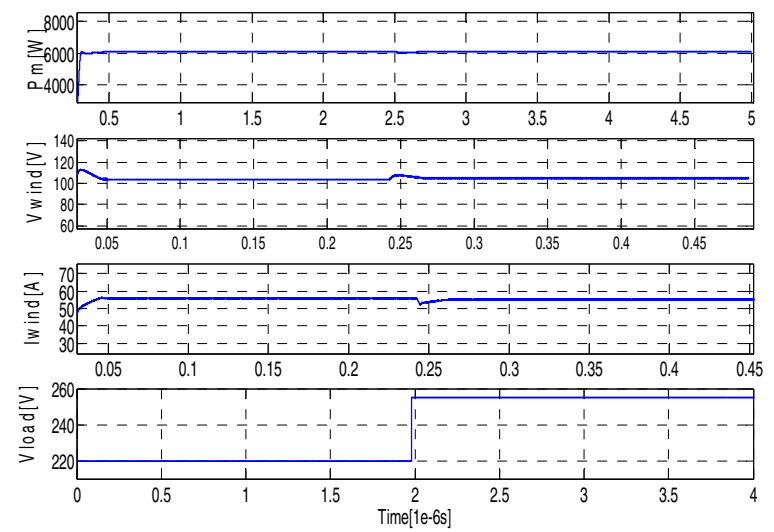

Fig. 8. Waveforms of the wind power, input voltage and current during the load voltage changes from $220 \mathrm{~V}$ to $255 \mathrm{~V}$.
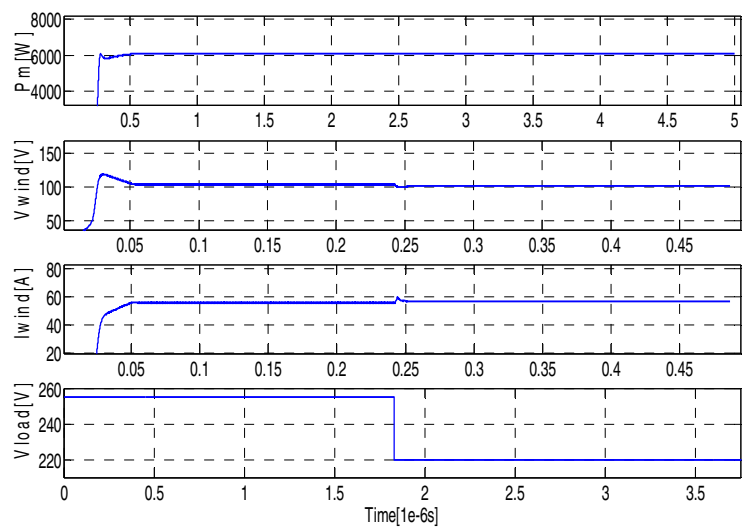

Fig. 9. Waveforms of the wind power, input voltage and current during the load voltage changes from $255 \mathrm{~V}$ to $220 \mathrm{~V}$.

The MPPT dynamic response of $\mathrm{P} \& \mathrm{O}$ and SM-ESC algorithms with constant wind speed are compared in Figure 10. From the comparison results, we can easily find the output power oscillations of SM-ESC method wind system are smaller than the P\&O method, and the wind MPP tracking speed under SM-ESC strategy is faster than the MPP tracking speed under $\mathrm{P} \& \mathrm{O}$ method. 


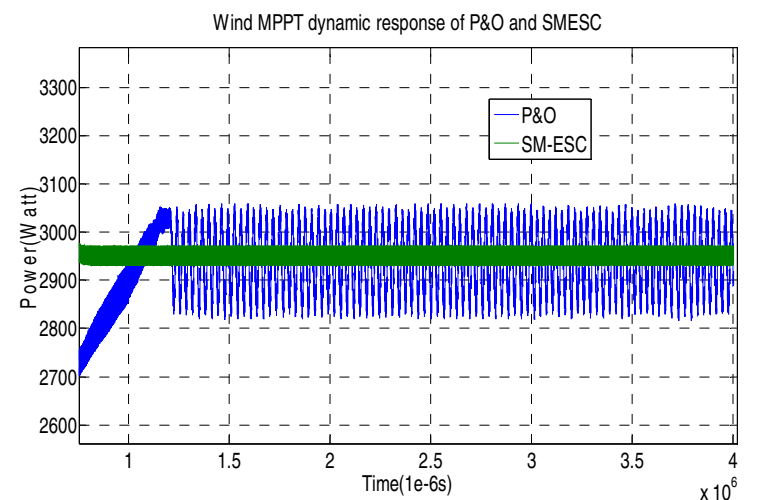

Fig. 10. Wind MPPT dynamic response of P\&O and SM-ESC

In addition, the MPPT control performances associated with load conditions of 300 Ah battery of $80 \%$ of SOC and CPL are shown in Figure 11 and Figure 12. The CPL changes from $5 \mathrm{~kW}$ to $2 \mathrm{~kW}$ in Figure 10 and changes from $4 \mathrm{~kW}$ to $6 \mathrm{~kW}$ in Figure 11. Both control effects represent the desired results.

In the beginning of Figure 11, CPL is $5 \mathrm{~kW}$ and wind speed is $6 \mathrm{~m} / \mathrm{s}$, there is no enough energy to supply the DC constant power load so it is necessary to discharge the battery and satisfy the CPL. Then the wind speed increases to $8 \mathrm{~m} / \mathrm{s}$, the total power generated from wind turbine is still smaller than $5 \mathrm{~kW}$, the gap power is still obtained from discharging of the battery. When the CPL decreases to $2 \mathrm{~kW}$ and the wind speed keeps at $8 \mathrm{~m} / \mathrm{s}$, which means the total power given by the wind source is higher than load power requirement and the surplus power can be used to charge the battery. Eventually, wind speed decreases to $6 \mathrm{~m} / \mathrm{s}$, the battery need to be discharged again to maintain the $2 \mathrm{~kW}$ DC constant power load.

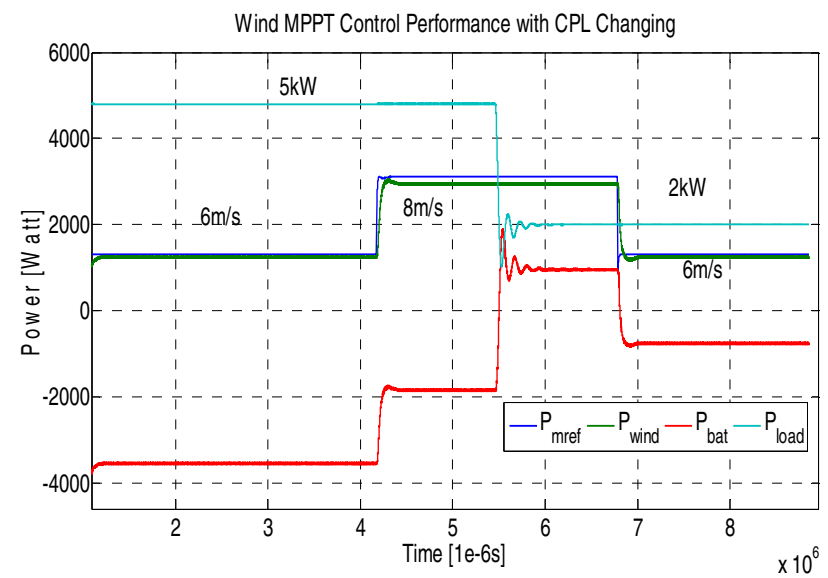

Fig. 11. MPPT control performance with the CPL changing from $5 \mathrm{~kW}$ to $2 \mathrm{~kW}$

For the Figure 12, CPL is $4 \mathrm{~kW}$ and wind speed is $10 \mathrm{~m} / \mathrm{s}$, the produced energy can supply the DC constant power load totally, the surplus power should be fully used to charge the battery. Then the wind speed decreases to $8 \mathrm{~m} / \mathrm{s}$, the total power generated from wind turbine decreases to about $3 \mathrm{~kW}$, which is smaller than $4 \mathrm{~kW}$, and the battery is discharged to make up energy deficiency. When there is a $2 \mathrm{~kW}$ power increment of the $\mathrm{CPL}$ and the wind speed keeps at $8 \mathrm{~m} / \mathrm{s}$, the same case as before which indicates that the battery continues to discharge and remain the load satisfaction. At last, wind speed increases to
$10 \mathrm{~m} / \mathrm{s}$, the total power generated from wind system is nearly the same as $6 \mathrm{~kW}$ of the constant power load. Therefore, the battery is under floating charged status with the DC bus voltage setting around the terminal voltage of the battery, which can maintain its capacity without the power loss.

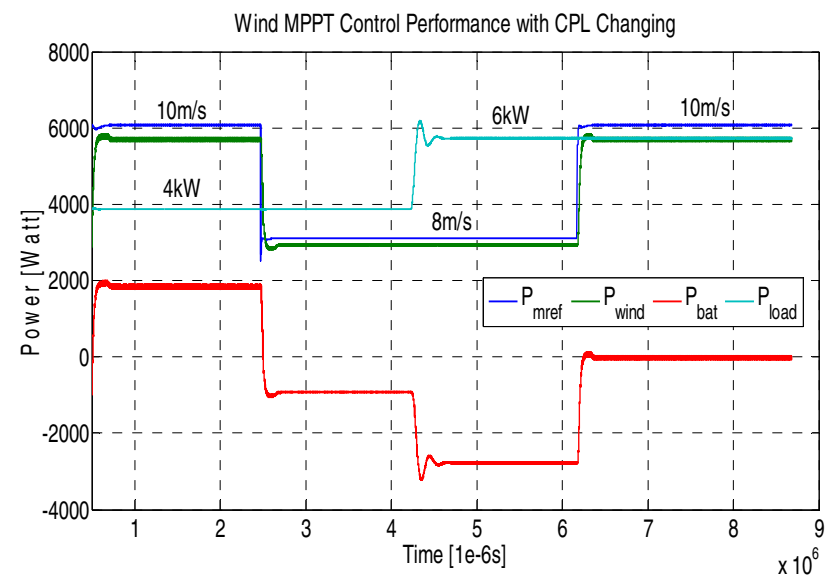

Fig. 12. MPPT control performance with the CPL changing from $4 \mathrm{~kW}$ to $6 \mathrm{~kW}$

\section{CONCLUSION}

This work was focused on the modeling of wind energy conversion system with DC constant power load, battery and a new MPPT method based on sliding mode control and extremum seeking control theory. Models of one wind power system, SM-ESC MPPT controllers and CPL were built in Matlab/Simulink. The boost converter can be effectively controlled by a sliding mode structure applying sliding layer concept which represents by a three states function. The specific parameters and operating principle regarding the SMESC are also introduced, therefore a sliding mode extremum seeking MPPT controller with adaptive step size can be established. The system responses with step change of DC bus voltage have also been illustrated and analyzed by using the controlled voltage source in the system load side. Simulation results demonstrated an accurate operation and validity of the proposed MPPT control strategy.

\section{REFERENCES}

[1] A. M. Gee, F. V. Robinson, and R. W. Dunn, "Analysis of battery lifetime extension in a small-scale wind-energy system using supercapacitors," 2013.

[2] A. Barchowsky, J. P. Parvin, G. F. Reed, M. J. Korytowski, and B. M. Grainger, "A comparative study of MPPT methods for distributed photovoltaic generation," in Innovative Smart Grid Technologies , IEEE PES, 2012, pp. 1-7.

[3] Shen D, Izadian A. Modeling and Control of A Combined WindSolar Microgrid, [C]//Industrial Electronics Society, IECON 2014-40th Annual Conference of the IEEE. 2014.

[4] A. Sannino, G. Postiglione, and M. H. J. Bollen, "Feasibility of a DC network for commercial facilities," IEEE Transactions on Industry Applications, vol. 39, no. 5, pp. 1499-1507, Sep. 2003.

[5] D. Nilsson, "DC distribution systems," Ph.D. dissertation, Chalmers University of Technology, Sweden, 2005.

[6] B. Fahimi, A. Kwasinski, A. Davoudi, R. S. Balog, and M. Kiani,"Powering a more electrified planet," IEEE power and energy magazine,no. 2, pp. 54-64, Aug. 2011. 
[7] Y.-C. Chang, C.-L. Kuo, K.-H. Sun, and T.-C. Li, "Development and operational control of two-string maximum power point trackers in DC distribution systems," IEEE Transactions on Power Electronics, vol. 28, no. 4, pp. 1852-1861, Apr. 2013.

[8] Ciampichetti, S., et al. "Sliding mode control of permanent magnet synchronous generators for wind turbines." IECON 201137th Annual Conference of the IEEE Industrial Electronics Society. 2011.

[9] Barakati S M, Kazerani M, Aplevich J D. Maximum power tracking control for a wind turbine system including a matrix converter, Energy Conversion, IEEE Transactions on, 2009, 24(3): 705-713.

[10] Cardenas R, Pena R. Sensorless vector control of induction machines for variable-speed wind energy applications, Energy Conversion, IEEE Transactions on, 2004, 19(1): 196-205.

[11] Abo-Khalil A G, Lee D C. MPPT control of wind generation systems based on estimated wind speed using SVR, Industrial Electronics, IEEE Transactions on, 2008, 55(3): 1489-1490.

[12] Koutroulis E, Kalaitzakis K. Design of a maximum power tracking system for wind-energy-conversion applications, Industrial Electronics, IEEE Transactions on, 2006, 53(2): 486494.

[13] Yu C, Chau K T. Thermoelectric automotive waste heat energy recovery using maximum power point tracking, Energy Conversion and Management, 2009, 50(6): 1506-1512.

[14] S. K. Korovin and V. I. Utkin. The Use of the Slip Mode in Problems of Static Optimization, Automatic and Remote Control, pp. 50-60, 1972.

[15] Korovin, S. K., and V. I. Utkin. "Using sliding modes in static optimization and nonlinear programming." Automatica 10.5 (1974): 525-532.
[16] Pan T, Ji Z, Jiang Z. Maximum power point tracking of wind energy conversion systems based on sliding mode extremum seeking control[C]//Energy 2030 Conference, 2008. ENERGY 2008. IEEE. 2008: 1-5.

[17] Ariyur K B, Krstic M. Real-time optimization by extremumseeking control [M]. Hoboken, USA: John Wiley \& Sons, 2003.

[18] Chen, J.-H.; Yau, H.-T.; Hung, W. Design and Study on Sliding Mode Extremum Seeking Control of the Chaos Embedded Particle Swarm Optimization for Maximum Power Point Tracking in Wind Power Systems. Energies 2014, 7, 1706-1720.

[19] Her-Terng Yau, Chih-Jer Lin, and Chen-Han Wu, "Sliding Mode Extremum Seeking Control Scheme Based on PSO for Maximum Power Point Tracking in Photovoltaic Systems," International Journal of Photoenergy, vol. 2013

[20] Shen D, Izadian A, Liao P. A hybrid wind-solar-storage energy generation system configuration and control[C]//Energy Conversion Congress and Exposition (ECCE), 2014 IEEE. IEEE, 2014: 436-442.

[21] Shen D, Izadian A. Sliding mode control of a DC distributed solar microgrid[C]/Power and Energy Conference at Illinois (PECI), 2015 IEEE. IEEE, 2015: 1-6.

[22] Krstić M, Wang H H. Stability of extremum seeking feedback for general nonlinear dynamic systems [J]. Automatica, 2000, 36(4): 595-601.

[23] Saghafinia A, Ping H W, Uddin M N, et al. Adaptive Fuzzy Sliding-Mode Control Into Chattering-Free IM Drive[J]. Industry Applications, IEEE Transactions on, 2015, 51(1): 692-701.

[24] Olalla C, Arteaga M I, Leyva R, et al. Analysis and comparison of extremum seeking control techniques[C]//IEEE ISIE Conf. 2007: 72-6. 